\title{
Experimental Design and Response Surface Modeling: A Method Development Application for the Determination of Reduced Inorganic Species in Environmental Samples
}

\author{
G. Hanrahan ${ }^{1,2 *}$, C. Garza ${ }^{3}$, E. Garcia ${ }^{1}$, and K. Miller ${ }^{1}$ \\ ${ }^{1}$ Department of Chemistry \& Biochemistry, California State University, Los Angeles, CA 90032, USA \\ ${ }^{2}$ Center for Environmental Analysis, California State University, Los Angeles, CA 90032, USA \\ ${ }^{3}$ National Oceanic and Atmospheric Administration (NOAA), Northeast Fisheries Science Center, Milford, CT 06460, USA
}

\begin{abstract}
To confirm the significance of reduced inorganic species in nature, it is important to develop sensitive and selective analytical techniques to detect these species in complex environmental matrices. As a model application, we report on the successful use of fractional factorial and Box-Behnken designs in factor screening, optimization and validation of an on-line flow-injection method for the determination of phosphite $[\mathrm{P}(+\mathrm{III})]$ in aqueous samples. Fractional factorial results indicated that the combined KI, $\mathrm{KIO}_{3}$ and ammonium molybdate flow rates, reaction temperature and $\mathrm{KIO}_{3}$ concentration were the most important single effects. The main interactive effects were between flow rate and reaction temperature, and between sample volume and reaction temperature. The Box-Behnken design further optimized the response with results confirming the significant single effects of flow rate and temperature as well as the interactive effects between flow rate and reaction temperature. Overall, the model from the Box-Behnken design predicted critical values as: flow rate $=0.40 \mathrm{~mL} \cdot \mathrm{min}^{-1}$, reaction temperature $=47^{\circ} \mathrm{C}$, sample volume $=85 \mu \mathrm{L}, \mathrm{KI}$ reagent concentration $=1.06 \mathrm{~g} \cdot \mathrm{L}^{-1}$ and $\mathrm{KIO}_{3}$ reagent concentration $=0.29 \mathrm{~g} \cdot \mathrm{L}^{-1} . \mathrm{P}(+\mathrm{III})$ determinations in spiked ultra-pure water were performed using the predicted optimized values from the Box-Behnken design and compared favorably with experimental results. In addition, the potential use of such methodology in the development of sensitive laboratory and field-based methods for the detection of a suite of reduced inorganic species in complex matrices was discussed.
\end{abstract}

Keywords: Box-Behnken design, fractional factorial design, optimization, reduced inorganic species, response surface modeling

\section{Introduction}

Recent developments have suggested significant roles for reduced inorganic species (e.g. arsenite, phosphite, sulphide) in metabolic processes and raises interesting questions regarding the biogeochemistry of these species in the environment (Salmassi et al., 2002; Macur et al., 2004; Morton and Edwards, 2005; Hanrahan et al., 2005a; Kim and Kim, 2006). Reduced phosphorus (P) compounds, in particular, have received considerable attention due to their detection in anaerobic sediments, sewage treatment facilities and increased use in industrial and agricultural processes leading to waste products (Morton and Edwards, 2005). Research has been conducted to provide an understanding of how $\mathrm{P}$ is cycled through the environment (Hanrahan et al., 2001; Gardolinski et al., 2004; Turner and Newman, 2006). However, a true understanding of the dynamics of $\mathrm{P}$ in the natural environment requires expanded knowledge of its oxidation-reduction (redox) cycling. Until recently, it had been assumed that the P species do not undergo redox reactions in the environment and exist solely in the phosphate, organic $\mathrm{P}$ esters (P-O-C bonds) and colloidal complex forms in aqueous systems (Delaney, 1998).

\footnotetext{
* Corresponding author: ghanrah@calstatela.edu
}

It is possible that reduced $\mathrm{P}$ compounds such as phosphite $\left[\mathrm{HPO}_{3}^{2-}, \mathrm{P}(+\mathrm{III})\right]$ are important in the overall cycling of $\mathrm{P}$, but their lifetimes may be too short to measure significant concentrations days or even hours after removing the samples from their natural environments for laboratory analysis. It is thus important to develop sensitive and selective analytical methods (with future potential for in situ or field-based deployments) of detection to help elucidate the role of reduced $\mathrm{P}$ species in natural systems.

To help address these issues, we have recently developed new batch and flow injection (FI) on-line methods for the determination of $\mathrm{P}(+\mathrm{III})$ based on the oxidation of $\mathrm{P}(+\mathrm{III})$ to $\mathrm{P}(+\mathrm{V})$ by a mixed-iodide solution containing tri-iodide $\left(\mathrm{I}_{3}{ }^{-}\right)$ and penta-iodide ( $\left.\mathrm{I}_{5}^{-}\right)$subunits (Barco et al., 2006). To date, the iodide methods presented above have not been developed for the determination of $\mathrm{P}(+\mathrm{III})$ in aqueous samples. Considering the significant role for phosphite and reduced $\mathrm{P}$ in microbiology and their possibly significant roles in the environment, sensitive techniques are necessary for the determination of $\mathrm{P}(+\mathrm{III})$. Given the generic and adaptive nature of both methods, it is believed that other analytes [e.g. $\mathrm{P}(+\mathrm{I}), \mathrm{As}(+\mathrm{III})]$ can be detected. In order to develop such methods and determine if full optimization has been achieved, proper experimental design and optimization techniques considering all the 
factors and their possible interactions must be performed.

Chemometric experimental design and optimization tools can be used to systematically evaluate and better understand the factors that influence a particular system by means of statistical approaches. Such approaches combine theoretical knowledge of experimental designs and a working knowledge of the particular factors to be studied. Fractional factorial designs are arguably the most widely used designs in experimental investigations, and mainly used for the screening portion of experiments. Such designs are good alternatives to a full factorial design, especially in the initial stage of a project, and considered a carefully prescribed and representative subset of a full factorial design (Araujo and Brereton, 1996; Otto, 1999; Hanrahan et al., 2005b). In fractional factorial designs, the number of experiments is reduced by a number $p$ according to a $2^{k-p}$ design. In the most commonly employed fractional design, the half-fraction design $(p=1)$, exactly one half of the experiments of a full design are performed. The fractional factorial design is based on an algebraic method of calculating the contributions of factors to the total variance with less than a full factorial number of experiments. Such designs are useful when the number of potential factors are relatively large [as examined in this study ( $n=5$ factors)] because they reduce the total number of runs required for the overall experiment.

Response surface methodology is designed to allow investigators estimating interactions, and therefore giving them an idea of the shape of the response surface they are studying. This approach is often used when simple linear and interaction models are not adequate, e.g. experimentation far from the region of optimum conditions (Meyers, 1971; Box et al., 1987). Here, the experimenter can expect the curvature to be more prevalent and will need a mathematical model which can represent the curvature. The simplest such model has the quadratic form (Equation 1):

$\mathrm{Y}=\beta_{0}+\beta_{1} X_{1}+\beta_{2} X_{2}+\beta_{12} X_{1} X_{2}+\beta_{11} X_{1}^{2}+\beta_{22} X_{2}^{2}$

which contains linear terms for all factors, squared terms for all factors, and products of all pairs of factors. In this study, for example, $X_{1}$ and $X_{2}$ terms correspond to reaction temperature and flow as they relate to predicting absorbance. In the above equation $\beta$ is the coefficient, akin to a regression coefficient. In other words it gives a measure of the rate of change in absorbance per unit change in reaction temperature or flow.

The Box-Behnken design is considered as an efficient option in response surface methodology and an ideal alternative to central composite designs (Deming and Morgan, 1993; Goupy, 1993). It has three levels per factor, but avoids the corners of the space, and fills in the combinations of center and extreme levels (Figure 1). Overall, it combines a fractional factorial with incomplete block designs to avoid the extreme vertices and to present an approximately rotatable design with only three levels per factor (Deming and Morgan, 1993).

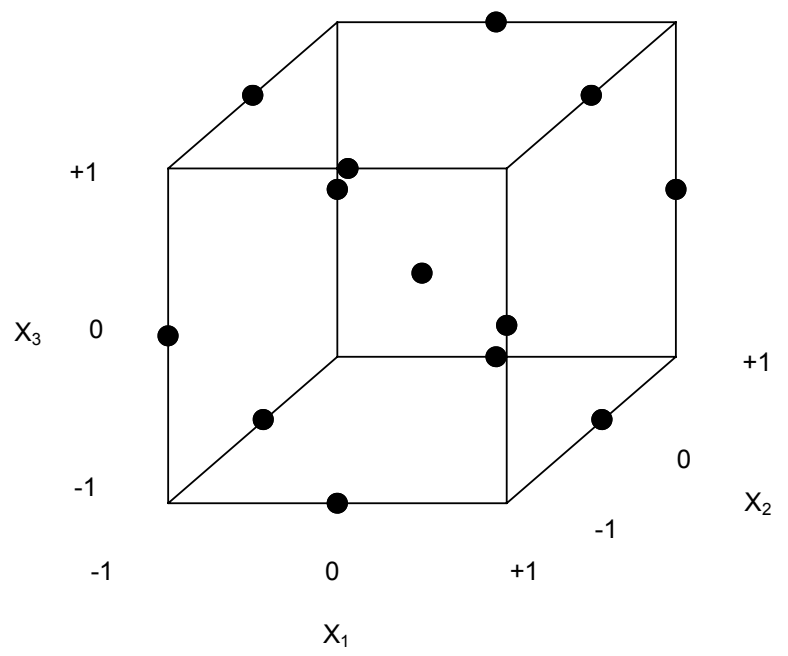

Figure 1. Box-Behnken design with three levels per factor (from Hanrahan et al., 2005b with permission of Elsevier).

In combination, these two strategies can help in optimizing FI experimental procedures in a reduced number of studies as well as providing essential information for appropriate decisions of the future of said procedure. This approach is opposite to the classical univariate approach. Univariate methods are time consuming (especially when multiple factors are being considered as in the described FI method) in that the response is investigated for each factor while all other factors are held at a constant level. This approach is relatively simple and suitable for factors that are independent. However, univariate methods do not take interactive effects between factors into account. If the effects are additive in nature, then the experimental designs are the optimum choice and require fewer measurements. A number of informative reviews and books (Brown and Bear, 1993; Araujo and Brereton, 1996; Gonźalez, 1998; Lundstedt, 1998; Festing, 2003; Gooding, 2004; Gemperline, 2006; Hanrahan and $\mathrm{Lu}, 2006 \mathrm{a}$ ) and original research articles (Zougagh et al., 2000; Izgi et al., 2000; Chen et al., 2001; Halliwell and Cass, 2001; Massumi et al., 2002; Vannecke et al., 2002; Rueda et al., 2003; Sanz et al., 2003; Klous et al., 2004; Hashemi et al., 2005; Hanrahan et al., 2006b) provide detailed information and applications of such techniques.

The purpose of this paper is to show the successful use of experimental design and response surface methodology in the optimization of a newly developed on-line method for the determination of $\mathrm{P}(+\mathrm{III})$ in aqueous samples. The applicability of the initial on-line method has been shown in the $\mathrm{P}(+\mathrm{III})$ determination of aqueous samples (Barco et al., 2006) using a univariate optimization approach. In this paper, the fractional factorial and Box-Behnken designs were employed to determine which factors (and their interactions) had the greatest influence on instrumental response. Results of each design and on-line method performance based on the optimized model are presented. In addition, future work involving the use of such designs in the development of in situ and field-based 
methods in the geothermal waters is considered. Overall, this work paves the way for the development of additional optimized on-line laboratory methods to detect other reduced inorganic species of interest.

\section{Materials and Methods}

\subsection{Instrumentation}

Experiments were conducted using a modified FIAlab Sequential Injection/Flow Injection Analysis unit (FIAlab Instruments, Model 3500) previously described in Barco et al. (2006). The optimized manifold used is shown in Figure 2 and consisted of a miniature fiber-optic spectrometer (Ocean Optics Inc., Dunedin, FL) with two 1024 element linear CCD arrays, a miniature halogen lamp (LS-1 Ocean Optics Inc., Dunedin, FL), a Lab-on-Valve micro channel multipurpose flow cell and an external water bath. PTFE tubing (Upchurch Scientific, Oak Harbor, WA, $0.8 \mathrm{~mm}$ i.d.) was used in all fluidic connections.

\subsection{Chemicals and Reagents}

All chemicals used were of analytical reagent grade and prepared with ultra-pure water (Millipore, 18.0 M $\Omega$ ). All containers, bottles and glassware used during this study were soaked overnight in a solution of $\mathrm{HCl}(10 \% \mathrm{v} / \mathrm{v})$ and rinsed three times with ultra-pure water and dried at room temperature. The potassium iodide (KI, Sigma) and potassium iodate $\left(\mathrm{KIO}_{3}\right.$, Mallinckrodt) solutions were prepared in ultra-pure water according to the concentration levels used in both the fractional factorial and Box-Behnken designs. The ammonium molybdate solution was prepared by dissolving $10 \mathrm{~g}$ of ammonium molybdate (Fisher) and $28 \mathrm{~mL}$ of $\mathrm{H}_{2} \mathrm{SO}_{4}$ into $1 \mathrm{~L}$ of ultra-pure water. The ascorbic acid (Fisher) solution was prepared by dissolving $5 \mathrm{~g}$ into $100 \mathrm{~mL}$ of ultra-pure water. $\mathrm{P}$ (+III) working standards in the range of 1.0 to $25 \mu \mathrm{M}$ were prepared daily from a stock $500 \mu \mathrm{M} \mathrm{Na} 2\left(\mathrm{PHO}_{3}\right) \cdot 5 \mathrm{H}_{2} \mathrm{O}$ solution for calibration experiments. A $10 \mu \mathrm{M}$ P (+III) standard was used for all fractional factorial and Box-Behnken design experiments.

\subsection{Colorimetric Reactions}

In the batch method the oxidation of $\mathrm{P}(+\mathrm{III})$ consumes free $\mathrm{I}_{3}^{-}$and $\mathrm{I}_{5}^{-}$in solution. The remaining $\mathrm{I}_{3}^{-}$and $\mathrm{I}_{5}^{-}$subunits are then allowed to react with the amylose content in starch to form a blue complex, which has a $\lambda_{\max }$ of $580 \mathrm{~nm}$. The on-line method employs the same reaction between the $\mathrm{P}(+\mathrm{III})$ and mixed-iodide producing phosphate $[\mathrm{P}(+\mathrm{V})]$ that is determined spectrophotometrically by a variation in the molybdenum blue method (Murphy and Riley, 1962) employing ascorbic acid at a $\lambda_{\max }$ of $710 \mathrm{~nm}$.

\subsection{Experimental Design and Optimization}

Preliminary experiments carried out using our initial univariate optimization approach (Barco et al., 2006) included the following variables: coil length, ascorbic acid concentra- tion and flow rate, ammonium molybdate concentration, combined $\mathrm{KI}, \mathrm{KIO}_{3}$ and ammonium molybdate flow rates $(0.42$ $\mathrm{mL} \min ^{-1}$ each in initial studies), reaction temperature, sample volume and $\mathrm{KI}$ and $\mathrm{KIO}_{3}$ concentrations. From these studies sample volume, reaction temperature, combined $\mathrm{KI}, \mathrm{KIO}_{3}$ and ammonium molybdate flow rates and $\mathrm{KI}$ and $\mathrm{KIO}_{3}$ concentrations were found to influence absorbance response appreciably.

In the present work, these five factors were chosen and tested at two levels in a fractional factorial design and three levels in a Box-Behnken design to achieve optimum conditions for $\mathrm{P}(+\mathrm{III})$ determination by the newly developed online method. The design matrix generated for the fractional factorial study $\left(2^{5-1}=16\right.$ experiments $)$ is shown in Table 1 . The design matrix generated for the Box-Behnken study (46 experiments) is shown in Table 2. Here, three center point experiments were incorporated to compute an estimate of the error term that does not depend on the fitted model. After generating the quadratic form (Equation 1) for the Box-Behnken relating the factors presented in Table 2, the process was optimized for the response $(Y)$. Optimization was performed to obtain the levels of $X_{1}-X_{5}$ (see specific model in section 3.2.) that maximized (highest absorbance) $Y$.

Our data were analyzed in JMP (SAS Institute) statistical software. In both the fractional factorial and Box-Behnken designs statistical significance was calculated in Analysis of Variance (ANOVA) models that were estimated and run up to their first order interaction terms. ANOVA for a linear regression partitions the total variation of a sample into components. These components are then used to compute an $F$-ratio that evaluates the effectiveness of the model. If the probability associated with the $F$-ratio is small, then the model is considered a better statistical fit for the data than the response mean alone. In our calculations we assumed that higher order interaction terms did not contribute significantly to the behavior of our statistical model. In each of our designs experiments were replicated three times so as to reduce the type I error rate and increase the power of our analyses.

As quality control, daily calibrations [0 to $25 \mu \mathrm{M} \mathrm{P}(+\mathrm{III})$ standards prepared in ultra-pure water] and intercomparison studies were performed (see section 3.4 for results). For the intercomparison study, the optimized FI method was compared to the batch method (reported in Barco et al., 2006) using spiked $[10 \mu \mathrm{M} \mathrm{P}(+\mathrm{III})]$ ultra-pure water samples.

\section{Results and Discussion}

\subsection{Fractional Factorial Design}

A fractional factorial design was used as the first optimization step. This initial approach is justified by the fact that, if we are far from the optimum, the most important data we need is that which indicates the direction in which to move in order to improve the response. When experiments were ranked according to highest response (Table 1), we noticed that experiments 7 gave us the largest absorbance reading (0.0358), followed by experiment $3(0.0343)$ and experiment $4(0.0256)$. 


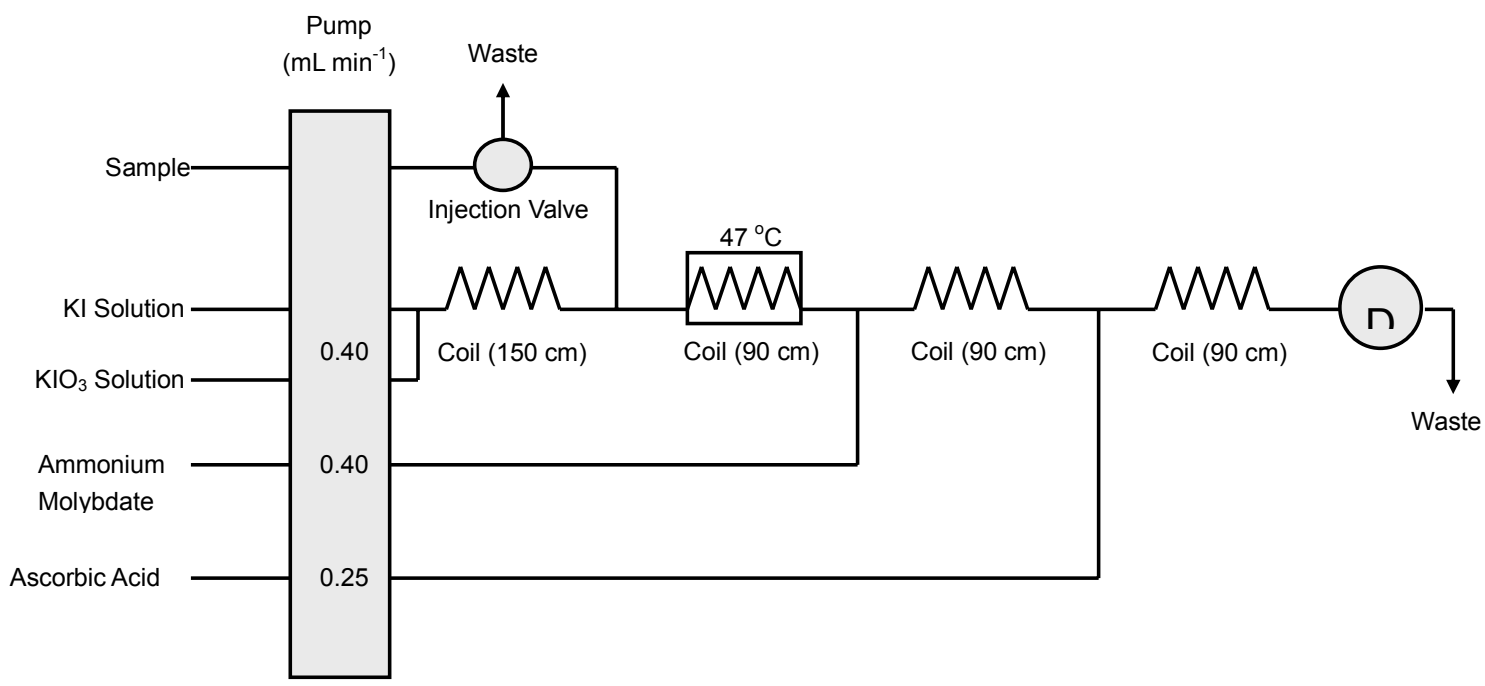

Figure 2. Schematic of the optimized FI manifold for the determination of phosphite in spiked ultra-pure water samples (modified from Barco et. al., 2006 with permission from Elsevier).

Table 1. Fractional Factorial Design Matrix with Instrumental Response in Spiked Ultra-Pure Water Samples

\begin{tabular}{|c|c|c|c|c|c|c|}
\hline Experiment & $\begin{array}{l}\text { Flow Rate } \\
\left(\mathrm{mL} \cdot \mathrm{min}^{-1}\right)\end{array}$ & $\begin{array}{c}\text { Reaction } \\
\text { Temperature } \\
\left({ }^{\circ} \mathrm{C}\right)\end{array}$ & $\begin{array}{l}\text { Sample Volume } \\
\left(\mathrm{mL} \cdot \mathrm{min}^{-1}\right)\end{array}$ & $\begin{array}{l}\text { KI Concentration } \\
\left(\mathrm{g} \cdot \mathrm{L}^{-1}\right)\end{array}$ & $\begin{array}{c}\mathrm{KIO}_{3} \\
\text { Concentration } \\
\left(\mathrm{g} \cdot \mathrm{L}^{-1}\right)\end{array}$ & $\begin{array}{c}\text { Mean Response } \\
\text { (Absorbance) } \\
(\mathrm{n}=3)\end{array}$ \\
\hline 1 & - & - & - & - & - & 0.0128 \\
\hline 2 & + & - & - & - & - & 0.0091 \\
\hline 3 & - & + & - & - & - & 0.0343 \\
\hline 4 & + & + & - & - & - & 0.0256 \\
\hline 5 & - & - & + & - & - & 0.0181 \\
\hline 6 & + & - & + & - & - & 0.0207 \\
\hline 7 & - & + & + & - & - & 0.0358 \\
\hline 8 & + & + & + & - & - & 0.0167 \\
\hline 9 & - & - & - & + & - & 0.0155 \\
\hline 10 & + & - & - & + & + & 0.0135 \\
\hline 11 & - & + & - & + & + & 0.0202 \\
\hline 12 & + & + & - & + & + & 0.0147 \\
\hline 13 & - & - & + & + & + & 0.0104 \\
\hline 14 & + & - & + & + & + & 0.0079 \\
\hline 15 & - & + & + & + & + & 0.0126 \\
\hline 16 & + & + & + & + & + & 0.0125 \\
\hline
\end{tabular}

* Flow rate: $(-)=0.30 \mathrm{~mL} \cdot \mathrm{min}^{-1},(+)=0.70 \mathrm{~mL} \cdot \mathrm{min}^{-1}$; Reaction Temperature: $(-)=40{ }^{\circ} \mathrm{C},(+)=60{ }^{\circ} \mathrm{C}$; Sample Volume: $(-)=50 \mu \mathrm{L},(+)=110 \mu \mathrm{L}$; KI Concentration: $(-)=0.50 \mathrm{~g} \cdot \mathrm{L}^{-1},(+)=1.50 \mathrm{~g} \cdot \mathrm{L} 1 ; \mathrm{KIO}_{3}$ Concentration: $(-)=0.10 \mathrm{~g} \cdot \mathrm{L}^{-1},(+)=0.40 \mathrm{~g} \cdot \mathrm{L}^{-1}$. 
Table 2. Box-Behnken Design Matrix with Instrumental Response in Spiked Ultra-Pure Water Samples

\begin{tabular}{|c|c|c|c|c|c|c|}
\hline Experiment & $\begin{array}{l}\text { Flow Rate } \\
\left(\mathrm{mL} \cdot \mathrm{min}^{-1}\right)\end{array}$ & $\begin{array}{c}\text { Reaction } \\
\text { Temperature } \\
\left({ }^{\circ} \mathrm{C}\right)\end{array}$ & $\begin{array}{c}\text { Sample } \\
\text { Volume } \\
\left(\mathrm{mL} \cdot \mathrm{min}^{-1}\right)\end{array}$ & $\begin{array}{c}\text { KI } \\
\text { Concentration } \\
\left(\mathrm{g} \cdot \mathrm{L}^{-1}\right)\end{array}$ & $\begin{array}{c}\mathrm{KIO}_{3} \\
\text { Concentration } \\
\left(\mathrm{g} \cdot \mathrm{L}^{-1}\right)\end{array}$ & $\begin{array}{l}\text { Mean Response } \\
\text { (Absorbance) } \\
(\mathrm{n}=3)\end{array}$ \\
\hline 1 & - & - & 0 & 0 & 0 & 0.0143 \\
\hline 2 & + & - & 0 & 0 & 0 & 0.0103 \\
\hline 3 & - & + & 0 & 0 & 0 & 0.0235 \\
\hline 4 & + & + & 0 & 0 & 0 & 0.0137 \\
\hline 5 & 0 & 0 & - & - & 0 & 0.0298 \\
\hline 6 & 0 & 0 & + & - & 0 & 0.0304 \\
\hline 7 & 0 & 0 & - & + & 0 & 0.0263 \\
\hline 8 & 0 & 0 & + & + & 0 & 0.0345 \\
\hline 9 & 0 & - & 0 & 0 & - & 0.0130 \\
\hline 10 & 0 & + & 0 & 0 & - & 0.0297 \\
\hline 11 & 0 & - & 0 & 0 & + & 0.0131 \\
\hline 12 & 0 & + & 0 & 0 & + & 0.0234 \\
\hline 13 & - & 0 & - & 0 & 0 & 0.0129 \\
\hline 14 & + & 0 & - & 0 & 0 & 0.0143 \\
\hline 15 & - & 0 & + & 0 & 0 & 0.0258 \\
\hline 16 & + & 0 & + & 0 & 0 & 0.0279 \\
\hline 17 & 0 & 0 & 0 & - & - & 0.0273 \\
\hline 18 & 0 & 0 & 0 & + & - & 0.0387 \\
\hline 19 & 0 & 0 & 0 & - & + & 0.0370 \\
\hline 20 & 0 & 0 & 0 & + & + & 0.0381 \\
\hline 21 & 0 & 0 & 0 & 0 & 0 & 0.0398 \\
\hline 22 & 0 & 0 & 0 & 0 & 0 & 0.0397 \\
\hline 24 & 0 & - & - & 0 & 0 & 0.0205 \\
\hline 25 & 0 & + & - & 0 & 0 & 0.0224 \\
\hline 26 & 0 & - & + & 0 & 0 & 0.0234 \\
\hline 27 & 0 & + & + & 0 & 0 & 0.0250 \\
\hline 28 & - & 0 & 0 & - & 0 & 0.0267 \\
\hline 29 & + & 0 & 0 & - & 0 & 0.0297 \\
\hline 30 & - & 0 & 0 & + & 0 & 0.0305 \\
\hline 31 & + & 0 & 0 & + & 0 & 0.0305 \\
\hline 32 & 0 & 0 & - & 0 & - & 0.0273 \\
\hline 33 & 0 & 0 & + & 0 & - & 0.0302 \\
\hline 34 & 0 & 0 & - & 0 & + & 0.0286 \\
\hline 35 & 0 & 0 & + & 0 & + & 0.0362 \\
\hline 36 & - & 0 & 0 & 0 & - & 0.0313 \\
\hline 37 & + & 0 & 0 & 0 & - & 0.0375 \\
\hline 38 & - & 0 & 0 & 0 & + & 0.0320 \\
\hline 39 & + & 0 & 0 & 0 & + & 0.0371 \\
\hline 40 & 0 & - & 0 & - & 0 & 0.0244 \\
\hline 41 & 0 & + & 0 & - & 0 & 0.0255 \\
\hline 42 & 0 & - & 0 & + & 0 & 0.0280 \\
\hline 43 & 0 & + & 0 & + & 0 & 0.0341 \\
\hline 44 & 0 & 0 & 0 & 0 & 0 & 0.0397 \\
\hline 45 & 0 & 0 & 0 & 0 & 0 & 0.0394 \\
\hline 46 & 0 & 0 & 0 & 0 & 0 & 0.0400 \\
\hline
\end{tabular}

* Flow rate: $(-)=0.30 \mathrm{~mL} \cdot \mathrm{min}^{-1},(0)=0.5 \mathrm{~mL} \cdot \mathrm{min}^{-1},(+)=0.70 \mathrm{~mL} \cdot \mathrm{min}^{-1}$; Reaction Temperature: $(-)=40{ }^{\circ} \mathrm{C},(0)=50{ }^{\circ} \mathrm{C},(+)=60{ }^{\circ} \mathrm{C} ;$ Sample Volume: $(-)=50 \mu \mathrm{L},(0)=80 \mu \mathrm{L},(+)=110 \mu \mathrm{L}$; KI Concentration: $(-)=0.10 \mathrm{~g} \cdot \mathrm{L}^{-1},(0)=0.25 \mathrm{~g} \cdot \mathrm{L}^{-1},(+)=0.40 \mathrm{~g} \cdot \mathrm{L}^{-1} ; \mathrm{KIO}_{3} \mathrm{Concentration}^{(-)}=$ $0.50 \mathrm{~g} \cdot \mathrm{L}^{-1},(0)=1.0 \mathrm{~g} \cdot \mathrm{L}^{-1},(+)=1.50 \mathrm{~g} \cdot \mathrm{L}^{-1}$. 
It was not immediately clear which factors contributed greatly, although our initial suspicions were reaction temperature, KI and $\mathrm{KIO}_{3}$ concentrations due to common levels for each of these factors in all three experiments. When examining the ANOVA results (Table 3), the most significant single effect was flow rate followed by reaction temperature. Interestingly, $\mathrm{KIO}_{3}$ was also fairly significant as an individual term but did not have substantial interactions with any other of the independent variables in the model. Among the interaction terms, flow rate/reaction temperature and sample volume/ reaction temperature were predicted to have the greatest effect on absorbance measurements in the fractional factorial design as they contributed the most to total variation in the model. Additionally, their $p$-values suggest that there is less than a $1 \%$ chance that the result is simply due to chance alone, a type I error.

Table 3. ANOVA Results for the Fractional Factorial Design

\begin{tabular}{|c|c|c|c|c|}
\hline $\begin{array}{l}\text { Source of } \\
\text { Variation }\end{array}$ & DF & $\begin{array}{l}\text { Sum of } \\
\text { Squares }\end{array}$ & f-ratio & $\mathrm{p}$-value \\
\hline Flow & 1 & 0.000361 & 4.54 & $<.0001$ \\
\hline Temp & 1 & 0.000562 & 9.97 & $<.0001$ \\
\hline Sample Volume & 1 & 0.000384 & 0.48 & 0.6346 \\
\hline KI & 1 & 0.001382 & 0.00 & 1.0000 \\
\hline $\mathrm{KIO}_{3}$ & 1 & 0.001505 & 3.33 & 0.0020 \\
\hline Flow/Temp & 1 & 0.000503 & 5.28 & $<.0001$ \\
\hline $\begin{array}{l}\text { Flow/Sample } \\
\text { Volume }\end{array}$ & 1 & 0.000000 & 0.68 & 0.5020 \\
\hline Flow/KI & 1 & 0.000281 & 3.31 & 0.0021 \\
\hline Flow $/ \mathrm{KIO}_{3}$ & 1 & 0.000000 & 0.00 & 1.0000 \\
\hline $\begin{array}{l}\text { Temp/Sample } \\
\text { Volume }\end{array}$ & 1 & 0.000461 & 4.40 & $<.0001$ \\
\hline Temp/KI & 1 & 0.000392 & 4.05 & 0.0003 \\
\hline $\mathrm{Temp} / \mathrm{KIO}_{3}$ & 1 & 0.000000 & 0.00 & 1.0000 \\
\hline $\begin{array}{l}\text { Sample } \\
\text { Volume/KI }\end{array}$ & 1 & 0.000251 & 2.13 & 0.0405 \\
\hline $\begin{array}{l}\text { Sample } \\
\text { Volume/KIO }\end{array}$ & 1 & 0.000000 & 0.00 & 1.0000 \\
\hline $\mathrm{KI} / \mathrm{KIO}_{3}$ & 1 & 0.000000 & 0.00 & 1.0000 \\
\hline Error & 36 & 0.000305 & & \\
\hline$r_{\text {adj }}^{2}$ & 0.7321 & & & \\
\hline Root mean square & 0.0291 & & & \\
\hline Mean of responses & 0.0175 & & & \\
\hline
\end{tabular}

\subsection{Box-Behnken Design}

Fractional factorial designs have been shown to have a major limitation, in that the main effects are often confounded with interaction terms (Araujo and Brereton, 1996). Taking this into account, along with the results achieved from the fractional factorial design, experiments aiming to determine if further optimization could be achieved were performed by a Box-Behnken design. As shown in Table 2, the three center point experiments $(21,22$ and 23$)$ gave the highest response
$($ mean $=0.0398)$, an increase of 0.004 absorbance units obtained from the fractional factorial design. ANOVA results (Table 4) revealed a significant interaction term between flow rate and reaction temperature. Though each term was significant separately (with reaction temperature having the greatest single effect), the noticeable interaction between the two factors suggests that the observed absorbance values were the product of the two terms (Table 4). Both the estimated $f$-ratio and sum of squares suggest that this interaction term contributed the greatest amount of variation in our model. Again, the $p$-value suggests that there is less than a $1 \%$ chance that our observed values were due to chance alone. A post-hoc review of our model revealed optimum critical values of flow rate $=0.40 \mathrm{~mL} \cdot \mathrm{min}^{-1}$, reaction temperature $=47{ }^{\circ} \mathrm{C}$, sample volume $=85 \mu \mathrm{L}$, KI reagent concentration $=1.06 \mathrm{~g} \cdot \mathrm{L}^{-1}$ and $\mathrm{KIO}_{3}$ reagent concentration $=0.29 \mathrm{~g} \cdot \mathrm{L}^{-1}$. Under the model optimized conditions, an absorbance value of 0.0366 A.U. [using a $10 \mu \mathrm{M} \mathrm{P}(+\mathrm{III})$ standard] was predicted, twice the value (0.0181 A.U.) of three previous pooled experimental runs of the same standard (Barco et al., 2006).

Table 4. ANOVA Results for the Box-Behnken Design

\begin{tabular}{|c|c|c|c|c|}
\hline Source of Variation & $\mathrm{DF}$ & $\begin{array}{l}\text { Sum of } \\
\text { Squares }\end{array}$ & f-ratio & p-value \\
\hline Flow & 1 & 0.003252 & 4.48 & 0.0363 \\
\hline Temp & 1 & 0.005514 & 7.60 & 0.0068 \\
\hline Sample Volume & 1 & 0.000470 & 0.64 & 0.4224 \\
\hline KI & 1 & 0.000180 & 0.24 & 0.6183 \\
\hline $\mathrm{KIO}_{3}$ & 1 & 0.000024 & 0.03 & 0.8532 \\
\hline Flow/Flow & 1 & 0.000031 & 0.04 & 0.8345 \\
\hline Flow/Temp & 1 & 0.009964 & 13.7 & 0.0003 \\
\hline Temp/Temp & 1 & 0.000789 & 1.08 & 0.2989 \\
\hline Flow/Sample Volume & 1 & 0.000000 & 0.00 & 0.9787 \\
\hline Temp/Sample Volume & 1 & 0.000000 & 0.00 & 0.9923 \\
\hline $\begin{array}{l}\text { Sample } \\
\text { Volume/Sample } \\
\text { Volume }\end{array}$ & 1 & 0.002606 & 3.59 & 0.0604 \\
\hline Flow/KI & 1 & 0.000006 & 0.00 & 0.9241 \\
\hline Temp/KI & 1 & 0.000019 & 0.02 & 0.8717 \\
\hline Sample Volume/KI & 1 & 0.000029 & 0.04 & 0.8398 \\
\hline $\mathrm{KI} / \mathrm{KI}$ & 1 & 0.000346 & 0.47 & 0.4907 \\
\hline Flow $/ \mathrm{KIO}_{3}$ & 1 & 0.000004 & 0.00 & 0.9395 \\
\hline $\mathrm{Temp} / \mathrm{KIO}_{3}$ & 1 & 0.000031 & 0.04 & 0.8364 \\
\hline Sample Volume $/ \mathrm{KIO}_{3}$ & 1 & 0.000016 & 0.02 & 0.8801 \\
\hline $\mathrm{KI} / \mathrm{KIO}_{3}$ & 1 & 0.000077 & 0.10 & 0.7443 \\
\hline $\mathrm{KIO}_{3} / \mathrm{KIO}_{3}$ & 1 & 0.000596 & 0.82 & 0.3664 \\
\hline Error & 117 & 0.084827 & & \\
\hline$r_{\text {adj }}^{2}$ & 0.9103 & & & \\
\hline Root mean square & 0.0269 & & & \\
\hline Mean of responses & 0.0283 & & & \\
\hline
\end{tabular}

The quadratic model from the Box-Behnken design allowed us to generate a response surface image and its asso- 
ciated contour lines for the main interaction flow rate/reaction temperature (Figure 3). Our generalized model, with interacttion terms, was estimated as (Equation 2):

$\mathrm{Y}=\beta_{0}+\beta_{1} T+\beta_{2} F+\beta_{12} T F+\beta_{11} T^{2}+\beta_{22} F^{2}$

where $\beta_{1}=$ coefficient for reaction temperature $(-0.000055)$, $\beta_{2}=$ coefficient for flow $(-0.027552), \beta_{12}=$ coefficient for interaction between reaction temperature and sample volume (0.0144083), $\beta_{11}=$ coefficient for reaction temperature squared $\left(3.025 \times 10^{-9}\right), \beta_{22}=$ coefficient for flow squared $(0.0008)$, $T=$ reaction temperature $(46.840905), F=$ flow $(0.4006), T^{2}=$ 2194.07, $F^{2}=0.0016$.

In Figure 3, it can be shown that appreciable variations in the response surface function occurs only when the two specified factors are varied. At higher flow rates it appears that a larger range of reaction temperatures can be tolerated, with a range of approximately 50 to $60{ }^{\circ} \mathrm{C}$. Ideally, reaction temperature should not be excessively high due to difficulties caused by the decrease of gas solubility in the heated solution. Gas evolution can cause bubbles within the tubing and ultimately affect the measurement signal. Overall, the interaction between flow rate and reaction temperature resulted in an improved absorbance measurement. The remaining independent variables, sample volume, $\mathrm{KI}$ and $\mathrm{KIO}_{3}$, were not significant in our model (Table 4), thus suggesting that our absorbance measurements should be relatively insensitive to variation in these terms. All interpretations of the response surface data illustrated how the equation and the computed confidence values were represented by the theoretical response surfaces. The dominance of particular terms could then be identified and used in the procedure of the analytical method described.

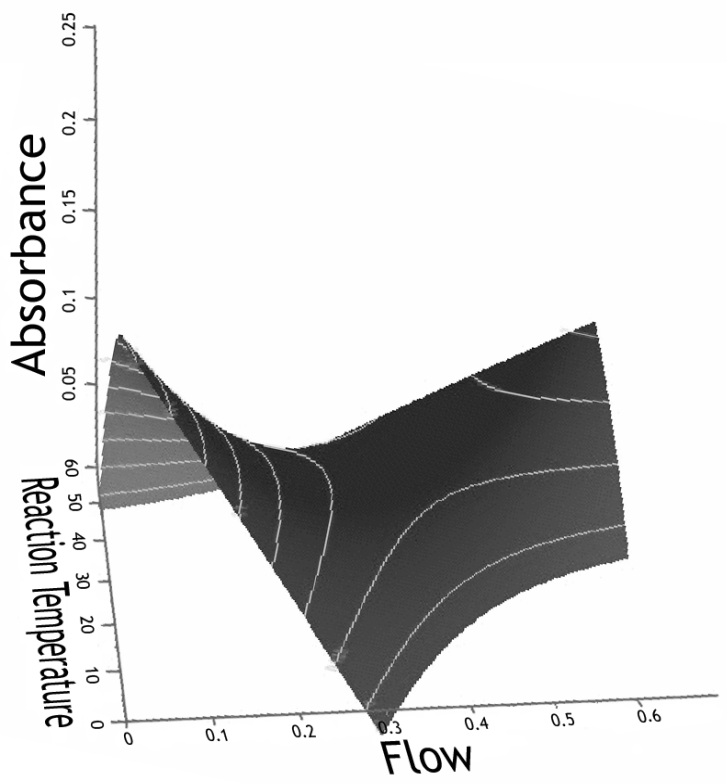

Figure 3. Box-Behnken generated response surface image for the main interaction flow rate/reaction temperature.

\subsection{Experimental vs Predicted Model Comparisons}

A series of five experimental runs [spiked $10 \mu \mathrm{M} P(+\mathrm{III})$ ultra-pure water, in triplicate] over a five day period at the optimum predicted Box-Behnken model values were conducted and the percentage difference from the predicted absorbance (0.0366 A.U.) was calculated (Table 5). Overall, experimental runs compared favorably (typically $<5.0 \%$ difference) to model predicted values with good reproducibility [relative standard deviation (R.S.D.) $<1.99 \%, n=3$ ]. These results indicate how successful this two-pronged chemometric approach can be in predicting the optimum values for FI experimental conditions.

\subsection{Method Performance}

In order to assess the performance of our optimized method, a series of three calibration studies using P (+III) spiked ultra-pure waters samples were performed. Replicate injecttions of standards ranging from 0 to $25 \mu \mathrm{M}$ was typically < $3.5 \%$ R.S.D. $(n=3)$ with linear regression coefficients of $r^{2}=$ 0.9983 . The limit of detection (LOD) for the optimized method $(0.13 \mu \mathrm{M})$ was determined as the analyte concentration giving a signal equal to the blank signal, $y_{\mathrm{b}}$, plus three times the standard deviation of the blank, $s_{\mathrm{b}}$. This is a significant improvement over previous univariate attempts $(\mathrm{LOD}=0.36$ $\mu \mathrm{M})$. Overall, a linear range of 0 to $50 \mu \mathrm{M}$ was achieved with an analysis rate of 45 samples $\mathrm{h}^{-1}$. An intercomparison study between the optimized on-line method and the batch method on spiked $[10 \mu \mathrm{M} \mathrm{P}(+\mathrm{III})]$ ultra-pure water samples was also undertaken (Barco et al., 2006). Statistically, a paired $t$-test showed no significant differences at $p=0.05$ (the critical value of $|t|$ was 2.57 and the calculated value of $|t|$ was 1.99). These results indicate that the innovative use of the response surface approach provided sensitive and accurate results for the determination of $\mathrm{P}(+\mathrm{III})$. Optimized conditions were achieved in a reduced number of experiments compared to what would have been achievable in traditional univariate methods.

\subsection{Interference Studies}

Extensive interference studies were previously performed on the chemistry developed (Barco et al., 2006). Here, we prepared solutions of reduced species relevant to natural waters: As(+III), N(+III) and S(+IV). The effect of each of these species was tested at concentrations mimicking the concentration of $\mathrm{P}(+\mathrm{III})$ in solution $(5$ and $25 \mu \mathrm{M})$. Additionally, oxidized forms of these elements $[\mathrm{As}(+\mathrm{V}), \mathrm{N}(+\mathrm{V})$, and $\mathrm{S}(+\mathrm{VI})$ were also tested under similar conditions. As $(+\mathrm{III})$ and $\mathrm{S}(+\mathrm{IV})$ presented significant interferences by behaving similarly to $\mathrm{P}(+\mathrm{III})$ in solution. These interferences were removed by pretreating $10 \mathrm{~mL}$ of the sample with $40 \mu \mathrm{L}$ of $0.01 \mathrm{M}$ potassium permanganate $\left(\mathrm{KMnO}_{4}\right)$ which effectively and simultaneously oxidized As(+III) and S(+IV).

Ultimately, we plan to use these methods for the detection of $\mathrm{P}(+\mathrm{III})$ [and other reduced inorganic species] in geothermal waters (e.g. hot springs), naturally occurring reducing environments that may be ideal locations for the detection of reduced inorganic species (McDowell et al., 2004). This work 
Table 5. Predicted vs Experimental Absorbance Measurements for Spiked [10 $\mu \mathrm{M}$ P(+III)] Ultra-Pure Water Samples Over a Five Day Period

\begin{tabular}{cccc}
\hline Experiment & Experimental Absorbance Reading (mean) & R.S.D. $(\%)(\mathrm{n}=3)$ & \% Difference* \\
\hline 1 & 0.0377 & 0.89 & 3.4 \\
2 & 0.0389 & 1.99 & 5.9 \\
3 & 0.0375 & 1.02 & 2.4 \\
4 & 0.0381 & 0.63 & 3.9 \\
5 & 0.0383 & 0.99 & 4.4 \\
\hline
\end{tabular}

* Percentage difference between experimental and the predicted model absorbance of 0.0366 .

will require more extensive examination of the possible interference from $\mathrm{P}(+\mathrm{IV})$ [in the case of $\mathrm{P}(+\mathrm{III})$ determination] and others depending on the analyte of interest. In the case of $\mathrm{P}(+\mathrm{III})$, it is recommended that we determine this species by the difference between the $\mathrm{P}(+\mathrm{V})$ found before and after the oxidation of $\mathrm{P}(+\mathrm{III})$ due to the presence of background $\mathrm{P}(+\mathrm{V})$ levels in the geothermal water matrix. Future studies will explore this extensively.

\section{Conclusions}

To confirm the significance of reduced inorganic species in nature, it is important to develop sensitive and selective analytical techniques to detect these species in complex matrices. As shown in this paper, adoption of experimental design and response surface modeling can significantly aid in this type of development. As a model study, we report the successful use of fractional factorial and Box-Behnken designs in screening, optimization and validation of a newly developed on-line method for $\mathrm{P}(+\mathrm{III})$ determination. Fractional factorial results showed that flow rate, reaction temperature and $\mathrm{KIO}_{3}$ concentration were the most important single effects. The Box-Behnken design optimized the response and confirmed the significance of flow rate and reaction temperature as single factors as well as a strong interactive effect between them. The optimized method showed good reproducibility and a significant improvement in the limit of detection for $\mathrm{P}(+\mathrm{III})$ compared to the previous univariate approach.

The next logical step would be to use such designs in the development and optimization of in situ and field-based instrumentation that is portable and able to measure a suite of reduced inorganic species in complex matrices (e.g. geothermal waters) in a contained and contaminant-free environment. We are currently in the process of such development and carefully considering sample matrix characteristics. Ultimately, this research will strengthen the scientific base underlying the design and application of such instrumentation and aid in elucidating the biogeochemical cycles of environmentally relevant species.

Acknowledgments. The authors greatly acknowledge the support from the National Science Foundation CEA-CREST program (\#HRD 9805529). G.H. also acknowledges partial support from the National Institutes of Health (1P20 MD001824-01). We also acknowledge Dr. Tina Salmassi, Dr. Crist Khachikian, Dr. Krishna Foster, Dr. Lin Ke,
Roman Barco and Deepa Patil for their collaborative efforts in the initial method development studies.

\section{References}

Araujo, P.W. and Brereton, R.G. (1996). Experimental design 1, screening. Trends Anal. Chem., 15, 26-31.

Barco, R.A., Patil, D.G., Xu, W., Ke, L., Khachikian, C.S., Hanrahan, G. and Salmassi, T.M. (2006). Development of iodide-based methods for batch and on-line determinations of phosphite in aqueous samples. Talanta, 69, 1292-1299.

Box, G.E.P., Hunter, W.G. and Hunter, J.S. (1987). Statistics for Experimenters: An Introduction to Design, Data Analysis and Model Building, John Wiley \& Sons, New York.

Brown, S.D. and Bear, R.S. (1993). Chemometric techniques in electrochemistry: A critical review. Crit. Rev. Anal. Chem., 24, 99-131.

Chen, J.G., Glancy, K., Chen, X. and Alasandro, M. (2001). Investigation of pharmaceutical high-performance liquid chromategraphy assay bias using experimental design. J. Chromatogr., 917, 63-73.

Delaney, M.L. (1998). Phosphorus accumulation in marine sediments and the oceanic phosphorus cycle. Global Biogeochem. Cycles, $12,563-573$.

Deming, S.N. and Morgan, S.L. (1993). Experimental Design: A Chemometric Approach, Elsevier, Amsterdam.

Festing, M.F.W. (2003). Principles: The need for better experimental design. Trends Pharmacol. Sci., 24, 341-345.

Gardolinski, P.C.F.C., Worsfold, P.J. and McKelvie, I.D. (2004). Seawater induced release and transformation of organic and inorganic phosphorus from river sediments. Water Res., 38, 688692.

Gonźalez, A.G. (1998). Two level factorial experimental designs based on multiple linear regression models: a tutorial digest illustrated by case studies. Anal. Chim. Acta, 360, 227-241.

Gemperline, P. (2006). A Practical Guide to Chemometrics, 2nd Edition, CRC Press, Boca Raton.

Gooding, O.W. (2004). Process optimization using combinatorial design principles: Parallel synthesis and design of experiment methods. Curr. Opin. Chem. Biol., 8, 297-304.

Goupy, J. (1993). Methods for Experimental Design: Principles and Applications for Physicists and Chemists, Elsevier, Amsterdam.

Halliwell, C.M. and Cass, A.E.G. (2001). A factorial analysis of silanization of conditions for the immobilization of oligonucleotides on glass surfaces. Anal. Chem., 73, 2476-2483.

Hanrahan, G., Gledhill, M., House, W.A. and Worsfold, P.J. (2001). Phosphorus loading in the Frome Catchment, UK: Seasonal refinement of the coefficient modelling approach. J. Environ. Qual., 30, 1738-1746.

Hanrahan, G., Salmassi, T.M., Khachikian, C.S. and Foster, K.L. (2005a). Reduced inorganic phosphorus in the natural environ- 
ment: significance, speciation and determination. Talanta, 66(2), 435-444.

Hanrahan, G., Zhu, J., Gibani, S. and Patil, D.G. (2005b). Chemometrics/Experimental Design, in Encyclopedia of Analytical Science, 2nd Edition, Elsevier, Oxford, pp. 8-13.

Hanrahan, G. and Lu, K. (2006a). Application of factorial and response surface methodology in modern experimental design and optimization. Crit. Rev. Anal. Chem, 36, 141-151.

Hanrahan, G., Tse, F., Dahdouh, F.T., Clarke, K. and Gomez, F.A. (2006b). Design and development of a flow-injection capillary electrophoresis analyzer employing fiber optic detection. $\mathrm{J}$. $\mathrm{Ca}$ pillary Electrophoresis Microchip Technol. (in press)

Hashemi, P., Bagheri, S. and Reza Fat'hi, M. (2005). Factorial design for optimization of experimental variables in preconcentration of copper by a chromotropic acid loaded Q-Sepharose adsorbent. Talanta, 68, 72-78

Izgi, B., Demir, C. and Gucer, S. (2000). Application of factorial design for mercury determination by trapping and graphite furnace atomic absorption spectrometry. Spectrochim. Acta. Part B At. Spectrosc., 55, 969-975.

Kim, D.J. and Kim, S.H. (2006). Effect of nitrite concentration on the distribution and competition of nitrite-oxidizing bacteria in nitration reactor systems and their kinetic characteristics. Water Res., 40, 887-894.

Klous, M.G., Nuijen, B., Van de Brink, W., Van Ree, J.M. and Beijnen, J.H. (2004). Process characterization, optimisation and validation of production of diacetylmorphine/caffeine sachets: a design of experiments approach. Int. J. Pharm., 285, 65-75.

Lundstedt, T., Seifert, E., Abramo, L., Thelin, B., Nyström, A., Petterson, J. and Bergman, R. (1998). Experimental design and optimization. Chemometrics Intell. Lab. Syst., 42, 3-40.

Macur, R.E., Langner, H.W., Kocar, B.D. and Inskeep, W.P. (2004) Linking geothermal processes with microbial community analysis: Successional dynamics in an arsenic-rich, acid-sulphatechloride geothermal spring. Geobiology, 2, 163-177.

Massumi, A., Najafi, N.M. and Barzegari, H. (2002). Speciation of $\mathrm{Cr}(\mathrm{VI}) / \mathrm{Cr}(\mathrm{III})$ in environmental waters by fluorimetric method using central composite, full and fractional factorial design. Microchem. J., 72, 93-101.

McDowell, M.M., Ivey, M.M., Lee, M.E., Firpo, V.V.D., Salmassi, T.M., Khachikian, C.S. and Foster, K.L. (2004). Detection of hypophosphite, phosphite and orthophosphate in natural geothermal water by ion chromatography. J. Chromatogr., 1039, 105-111.

Morton, S.C., Glindemann, D., Wang, X., Niu, X. and Edwards, M. (2005). Analysis of reduced phosphorus in samples of environmental interest. Environ. Sci. Technol., 39, 4369-4376.

Murphy, J. and Riley, J.P. (1962). A modified single solution method for the determination of phosphate in natural waters. Anal. Chim. Acta, 27, 31-36.

Myers, R.M. (1971). Response Surface Methodology, Allyn and Bakon, Boston.

Otto, M. (1999). Chemometrics: Statistics and Computer Applications in Analytical Chemistry, Wiley-VCH, Chichester.

Rueda, M.E., Sarabia, L.A., Herrero, A. and Ortiz, M.C. (2003). Optimisation of a flow injection system with electrochemical detection using the desirability function. Application to the determination of hydroquinone in cosmetics. Anal. Chim. Acta, 479, 173-184.

Salmassi, T.M., Venkateswaren, K., Satomi, M., Nealson, K., Newman, D.K. and Hering, J.G. (2002). Oxidation of Arsenite by Agrobacterium albertimagni, AOL15, sp. nov., isolated from Hot Creek, California. Geomicrobiol. J., 19, 53-66.

Sanz, J., de Diego, A., Raposo, J.C. and Madariaga, J.M. (2003). Routine analysis of mercury species using commercially available instrumentation: Chemometric optimisation of the instrumental variables. Anal. Chim. Acta, 486, 255-267.

Turner, B.L. and Newman, S. (2005). Phosphorus cycling in wetland soils: the importance of phosphate diesters. J. Environ. Qual., 34, 1921-1929.

Vannecke, C., Bloomfield, M.S., Vander Heyden, Y. and Massart, D.L. (2002). Development of a generic flow-injection analysis method for compounds with a secondary amine or amide function, using an experimental design approach Part II, Selection and evaluation of the chemical reaction parameters. Anal. Chim. Acta, 455, 117-130.

Zougagh, M., Rudner, P.C., de Torres, A.M. and Cano Pavon, J.M. (2000). Application of Doehlert matrix and factorial designs in the optimization of experimental variables associated with the on-line preconcentration and determination of zinc by flow injecttion inductively coupled plasma atomic emission spectrometry. J. Anal. At. Spectrom., 15, 1589-1594. 